\title{
Correction to: Bisphosphonates and mortality: confounding in observational studies
}

\author{
J. Bergman ${ }^{1}$ - A. Nordström ${ }^{2,3}$ - A. Hommel ${ }^{4}$ - M. Kivipelto ${ }^{5,6,7}$ • P. Nordström ${ }^{1}$ \\ Published online: 19 February 2021 \\ (C) The Author(s) 2021
}

Correction to: Osteoporosis International (2019) 30: 1973-1982, https://doi.org/10.1007/s00198-019-05097-1

The original version of this article, published on 31 July 2019, unfortunately contained a mistake.

We regret to inform readers of an error in our original publication [1]. Contrary to what is claimed in the abstract, the analysis did not include a variable on the type of surgical procedure performed, as this variable was unintentionally left out of the analysis. In a rerun of

The online version of the original article can be found at https://doi.org/ 10.1007/s00198-019-05097-1

P. Nordström

peter.nordstrom@umu.se

1 Unit of Geriatric Medicine, Department of Community Medicine and Rehabilitation, Umeå University, 90187 Umeå, Sweden

2 Section of Sustainable Health, Department of Public Health and Clinical Medicine, Umeå University, 90187 Umeå, Sweden

3 School of Sport Sciences, UiTArctic University of Norway, Postboks 1621, 9509 Alta, Norway

4 Department of Care Sciences, Malmö University, 20506 Malmö, Sweden

5 Division of Clinical Geriatrics, Department of Neurobiology, Care Sciences and Society, Karolinska Institutet, Plan 7, 14183 Huddinge, Sweden

6 Theme Aging, Karolinska Univeristy Hospital, 14186 Stockholm, Sweden

7 Research and Development Unit, Stockholm Sjukhem, Mariebergsgatan 22, 11219 Stockholm, Sweden the analysis, we excluded 28 persons in the eligible cohort $(\mathrm{n}=49,765)$ who were missing data on type of surgical procedure. Among the remaining 49,737 persons, $66.6 \%(\mathrm{n}=33,118)$ were treated with internal fixation, $33.0 \%(n=16,418)$ with hemiarthroplasty or total hip arthroplasty, and $0.4 \%(n=201)$ with other or no treatment. The association between bisphosphonate use and mortality was unchanged after adjustment for type of surgical procedure and the other confounders (fully-adjusted hazard ratio [HR] $0.85,95 \%$ confidence interval [CI] 0.80-0.90).

Matching on type of surgical procedure and the other confounders resulted in a sub-cohort of 5,108 bisphosphonate users and 5,108 controls. Similar numbers of bisphosphonate users and controls were treated with internal fixation $(3,444$ [67.4\%] and 3,462 [67.8\%], standardized mean difference [SMD] 0.01), hemiarthroplasty or total hip arthroplasty $(1,647$ [32.2\%] and 1,631 [31.9\%]; SMD 0.01), and other or no treatment (17 [0.3\%] and 15 [0.3\%]; SMD 0.01). The association between bisphosphonate use and mortality (HR $0.84,95 \%$ CI $0.79-0.91$ ) was similar to that presented in the original publication. The Kaplan-Meier curves and risk ratio curves showed lower mortality in the bisphosphonate group from day 2 of follow-up, instead of from day 6, as in the original analysis (Fig. 1 and Fig. 2). In the updated analysis, the association was significant from the second month of follow-up, instead of from the second week of follow-up, as in the original analysis.

This updated analysis confirms our original conclusion that the mortality rate is lower in bisphosphonate users soon after treatment initiation. However, this association was not statistically significant as early as was shown in the original analysis. We apologize for the error. 


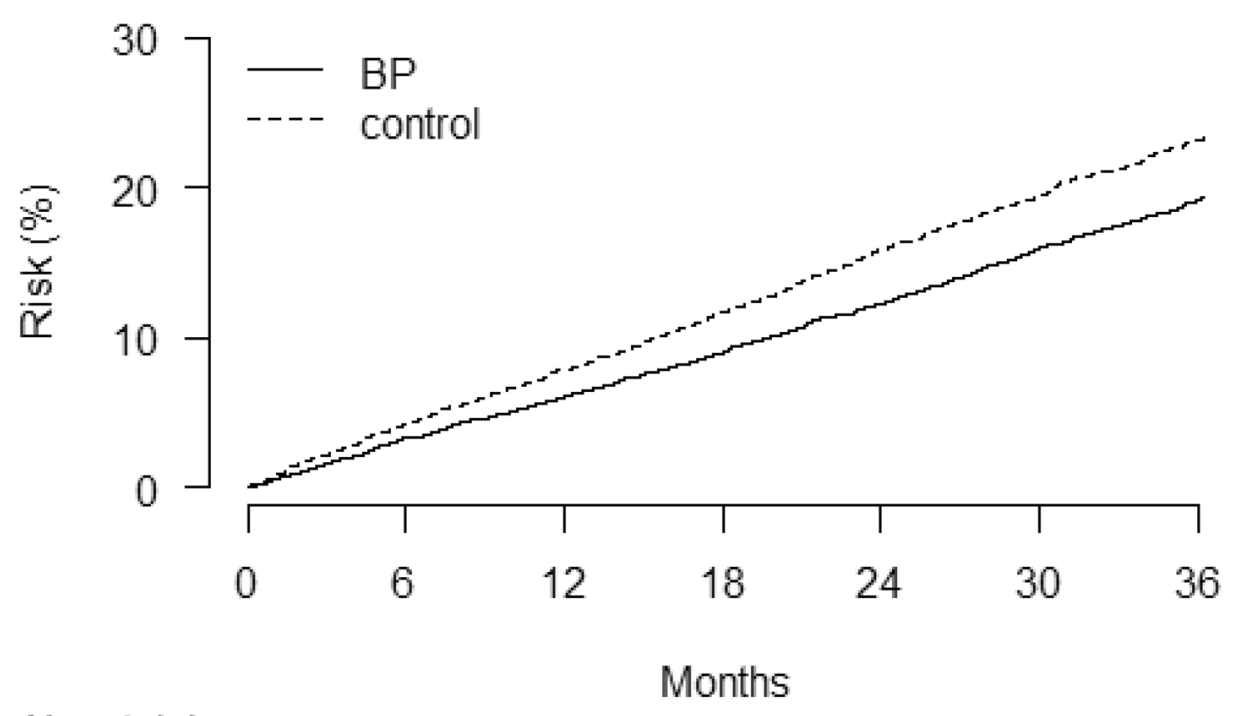

No. at risk

$\begin{array}{llllllll}\text { BP } & 5108 & 4770 & 4311 & 3816 & 3288 & 2854 & 2424\end{array}$

$\begin{array}{llllllll}\text { Control } & 5108 & 4747 & 4333 & 3804 & 3314 & 2913 & 2508\end{array}$

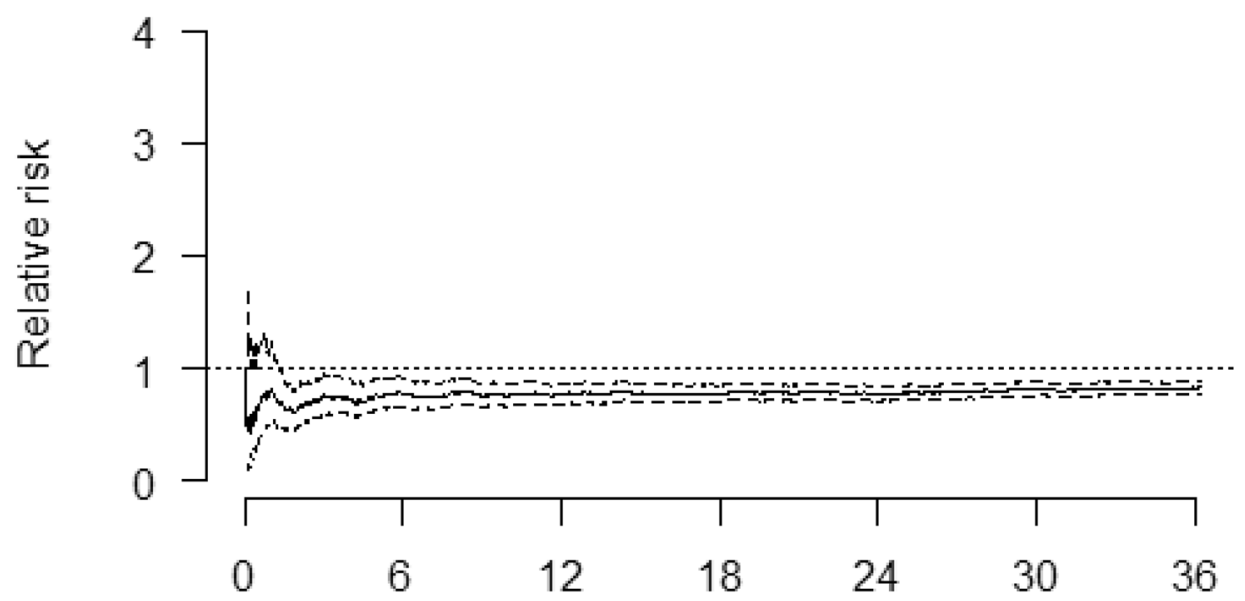

No. of deaths

$\begin{array}{llllllll}\mathrm{BP} & 0 & 166 & 299 & 425 & 555 & 684 & 789\end{array}$

$\begin{array}{llllllll}\text { Control } & 0 & 215 & 392 & 560 & 734 & 868 & 997\end{array}$




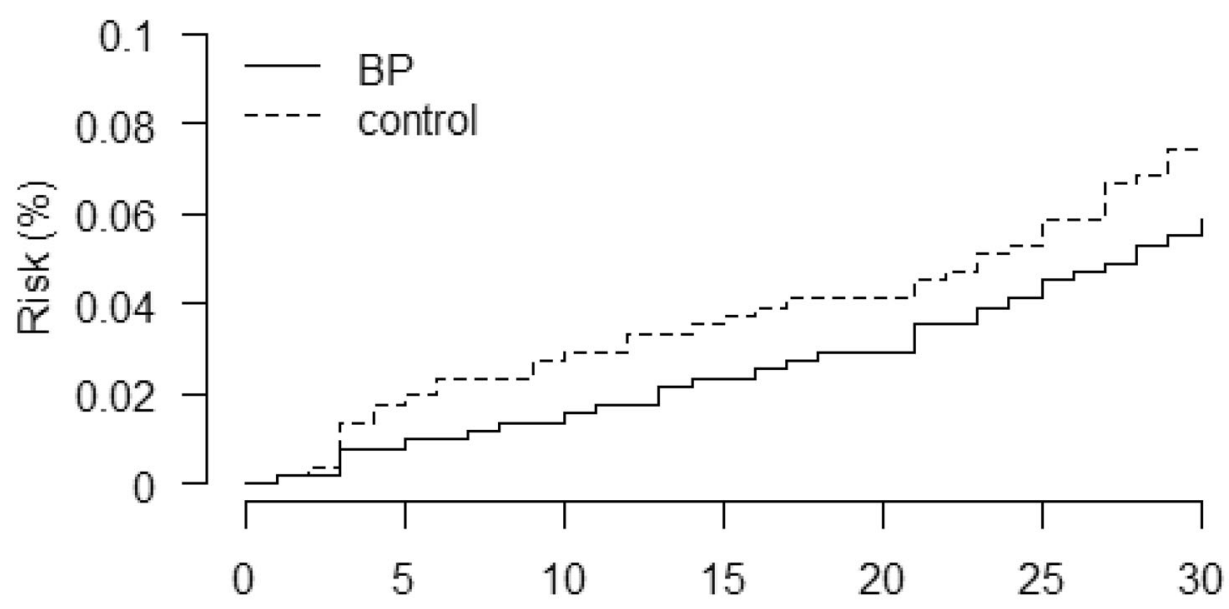

No. at risk

Days

$\begin{array}{llllllll}\text { BP } & 5108 & 5101 & 5095 & 5086 & 5079 & 5069 & 5058\end{array}$

$\begin{array}{llllllll}\text { Control } & 5108 & 5094 & 5088 & 5078 & 5069 & 5061 & 5049\end{array}$

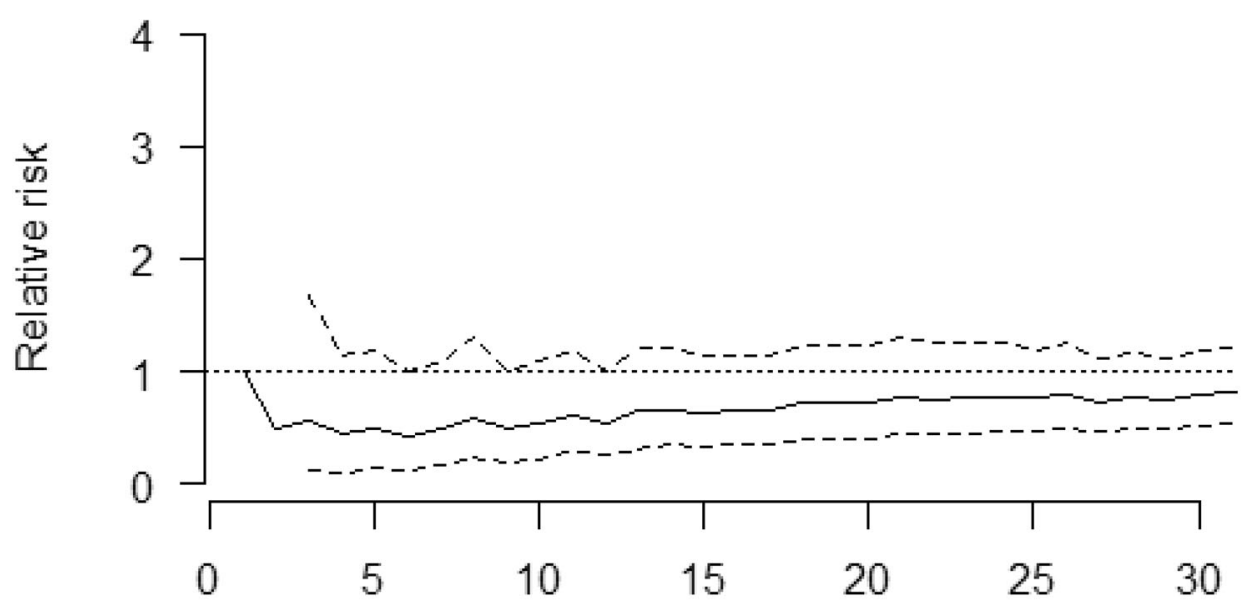

No. of deaths

$\begin{array}{llcccccc}\text { BP } & 0 & 5 & 8 & 12 & 15 & 23 & 30 \\ \text { Control } & 0 & 10 & 15 & 19 & 21 & 30 & 38\end{array}$


Open Access This article is licensed under a Creative Commons Attribution-NonCommercial 4.0 International License, which permits any non-commercial use, sharing, adaptation, distribution and reproduction in any medium or format, as long as you give appropriate credit to the original author(s) and the source, provide a link to the Creative Commons licence, and indicate if changes were made. The images or other third party material in this article are included in the article's Creative Commons licence, unless indicated otherwise in a credit line to the material. If material is not included in the article's Creative Commons licence and your intended use is not permitted by statutory regulation or exceeds the permitted use, you will need to obtain permission directly from the copyright holder. To view a copy of this licence, visit http:// creativecommons.org/licenses/by-nc/4.0/.

\section{Reference}

1. Bergman J, Nordström A, Hommel A, Kivipelto M, Nordström $P$ (2019) Bisphosphonates and mortality: confounding in observational studies? Osteoporos Int 30:1973-1982. https://doi.org/10.1007/ s00198-019-05097-1

Publisher's note Springer Nature remains neutral with regard to jurisdictional claims in published maps and institutional affiliations. 